\title{
PENGEMBANGAN DAN ANALISIS SOAL HIGHER ORDER THINKING SKILLS BERBASIS ALAM DAN BUDAYA PAPUA
}

\author{
Benidiktus Tanujaya, Jeinne Mumu \\ Universitas Papua, Jalan Gunung Salju, Manokwari 98314 Papua Barat, Indonesia \\ E-mail: b.tanujaya@unipa.ac.id
}

\begin{abstract}
Abstrak
Kemampuan berfikir tingkat tinggi (Higher Order Thinking Skills) siswa di Indonesia, termasuk siswa di Papua, masih tergolong sangat rendah. Di lain pihak, alam dan budaya Papua, berpotensi untuk dijadikan instrumen atau konteks dalam mengembangkan soal yang dapat mengembangkan Higher Order Thinking Skills (HOTS) siswa, khususnya dalam pembelajaran matematika. Penelitian ini bertujuan untuk mengembangkan dan menganalisis soal HOTS yang berbasis alam dan budaya. Produk yang dikembangkan adalah butir soal HOTS, dengan prosedur penetapan konteks, pengembangan butir soal, uji validitas butir soal, dan analisis lebih lanjut. Hasil penelitian menunjukkan bahwa soal HOTS matematika dapat dikembangkan dengan menggunakan konteks Alam dan Budaya Papua. Hasil ini berkontribusi untuk menggugah pendidik dan peneliti lainnya untuk mengembangkan soal-soal HOTS berbasis alam dan budaya Papua, baik dalam mata pelajaran matematika maupun mata pelajaran lainnya.
\end{abstract}

Kata Kunci: Ethnic HOTS, Alam dan Budaya Papua, Pengembangan HOTS

\begin{abstract}
Higher Order Thinking Skills of students in Indonesia, including students in Papua, are still very low. On the other hand, Papua's nature and culture have the potential to be used as an instrument or context in developing questions that can develop students' Higher Order Thinking Skills (HOTS), especially in mathematics learning. This study aims to create and analyze HOTS questions based on nature and culture. The products developed were HOTS items, with the procedure for determining the context, expanding the items, testing the items' validity, and further analysis. The results showed that HOTS mathematics questions could be developed using Papua's Nature and Culture context. These results contribute to inspiring educators and other researchers to establish HOTS questions based on Papua's nature and culture, both in mathematics and other subjects.
\end{abstract}

Keywords: Ethnic HOTS, Nature and Culture of Papua, HOTS Development

\section{PENDAHULUAN}

Matematika merupakan salah satu mata pelajaran mempunyai peranan dalam mengembangkan HOTS siswa (Tanujaya, Prahmana, \& Mumu, 2017). HOTS atau Higher Order Thinking Skills merupakan kemampuan kognitif pada tiga level teratas, yaitu analisis, sintesis, dan evaluasi. HOTS juga sering dikenal sebagai keterampilan berpikir yang tersusun dari beberapa dimensi, seperti keterampilan berpikir kritis, kreatif, desain, 
dan system (Moore \& Stanly, 2010; Tanujaya, Mumu, \& Margono, 2017).

HOTS seorang siswa muncul pada waktu siswa menghadapi persoalan yang tidak dikenal, tidak terduga, dilema, atau yang merupakan informasi-informasi baru lainnya. Ketika menghadapi permasalahan tersebut, siswa yang memiliki HOTS, akan menyimpannya dalam ingatan mereka, kemudian secara langsung mengompilasi fakta, dan menghubungkan ke pengetahuan yang sudah ada, dalam rangka memperoleh strategi yang baru untuk mencapai tujuan atau menyelesaikan permasalahan yang dihadapi tersebut (Yee, dkk. 2015).

Menyadari akan hal tersebut, maka HOTS merupakan suatu keterampilan berpikir yang harus dimiliki oleh seorang mahasiswa untuk menghadapi masa depan, khusus menghadapi revolusi industri 4.0, bahkan mungkin pada revolusi industri 5.0. Pada masa tersebut, segala sesuatu belum kita tahu bentuk dan rupanya. HOTS diharapkan dapat membantu pada mahasiswa setelah mereka lulus dari perguruan tinggi.

Salah satu permasalahan utama saat ini bagi para calon tenaga kerja yang dipersiapkan di Perguruan Tinggi adalah perbedaan antara apa yang mereka pelajari saat ini dan apa yang harus dilakukan pada waktu mereka terjun ke masyarakat. Perbedaan antara bekal yang diperoleh di kampus dan jenis pekerjaan yang belum terprediksi saat ini. Perbedaan tersebut merupakan dampak dari perkembangan ilmu pengetahuan dan teknologi, khususnya Teknologi Informasi dan Komunikasi (TIK).

Siapakah yang dapat memprediksi Guru dengan kompetensi bagaimanakah yang dibutuhkan pada 10 tahun yang akan datang? atau lebih ekstremnya, kita patut bertanya, apakah profesi guru masih dibutuhkan pada saat tersebut? Saat ini saja, perkembangan TIK telah menggeser guru sebagai sumber belajar utama, menjadi hanya salah satu sumber belajar. Bahkan mungkin saja, guru bukan sumber belajar lagi, jika pendidikan profesi guru tidak melakukan pembenahan.

Persoalan yang sama juga dihadapi oleh para lulusan Perguruan Tinggi lainnya. Persoalan-persoalan tersebut menyebabkan mahasiswa membutuhkan kemampuan berpikir tingkat tinggi. Keterampilan berpikir ini akan memampukan mereka untuk berkompetisi pada masa depan yang tidak menentu, masa yang penuh dengan ketidakpastian. Masa di mana manusia harus mampu mengelola ketidakpastian menjadi kepastian.

Oleh karena itu, Perguruan Tinggi harus mampu menyiapkan para lulusannya 
menghadapi perkembangan sekaligus tantangan tersebut. Penyesuaian kurikulum, materi pembelajaran, dan berbagai perangkat lainnya perlu dilakukan. Perguruan Tinggi tidak boleh berdiam diri karena dengan demikian, maka akan terlindas oleh kemajuan teknologi. Salah satu hal yang perlu dilakukan adalah mengembangkan HOTS siswa, khususnya dalam pembelajaran matematika.

Pentingnya HOTS siswa dalam pembelajaran matematika sudah disadari oleh Pemerintah Indonesia. Pengembangan HOTS siswa tercantum dalam Kurikulum Nasional. Dalam kurikulum pembelajaran matematika, baik dalam Kurikulum KTSP (Kurikulum tahun 2006) maupun Kurikulum 13 (K-13), dinyatakan bahwa tujuan pembelajaran matematika adalah mengembangkan kemampuan berpikir siswa (Kemdiknas, 2006), khususnya keterampilan berpikir kritis, kreatif, kolaboratif dan komunikatif (Kemdikbud, 2013), yang merupakan unsur-unsur HOTS.

Namun demikian, sampai sejauh ini belum ada penelitian yang secara khusus mengukur tentang HOTS dari siswa matematika di Indonesia. Pengukuran yang dilakukan secara sporadis dan pada skala lokal pada kelas-kelas penelitian dengan jumlah subyek yang terbatas. Namun demikian, terdapat hasil penelitian yang dilakukan oleh Lembaga internasional, seperti PISA, yang dapat dijadikan sebagai indikator tentang HOTS siswa matematika di Indonesia. Hasil survei PISA disajikan pada Tabel 1.

Tabel 1. Kinerja Matematika Siswa di Indonesia berdasarkan Hasil PISA

\begin{tabular}{cccc}
\hline No & Tahun & Skor Rata-rata & Ranking \\
\hline 1 & 2003 & 362.2 & 38 dari 40 \\
2 & 2006 & 399.0 & 48 dari 56 \\
3 & 2009 & 371.0 & 61 dari 65 \\
4 & 2012 & 375.0 & 64 dari 65 \\
5 & 2015 & 386.0 & 65 dari 72 \\
6 & 2018 & 379.0 & 74 dari 79 \\
\hline
\end{tabular}

Sumber: PISA Reports: 2003 - 2018

Tabel 1 memberikan informasi bahwa tidak ada perkembangan yang signifikan dari nilai rata-rata skor PISA siswa Indonesia dalam bidang matematika. Sejak tahun 2003, di mana PISA mulai dilaksanakan dan Indonesia sudah berperan serta, skor PISA siswa Indonesia tidak menunjukkan perkembangan yang signifikan. Skor PISA siswa 
Indonesia, selalu berada pada ranking terbawah dari seluruh negara peserta PISA.

Informasi tersebut juga menyatakan bahwa terdapat kekeliruan dalam pembelajaran matematika di Indonesia. Kekeliruan apa saja yang terjadi dalam pembelajaran matematika di Indonesia? Upaya apa saja yang perlu dilakukan untuk memperbaiki hal tersebut, khususnya di Tanah Papua?

Hasil penelitian menunjukkan beberapa kekeliruan yang terjadi namun terus dipertahankan dalam sistem Pendidikan kita, khususnya dalam pembelajaran matematika, antara lain: (1) buku teks dan LKS siswa yang digunakan tidak mengembangkan HOTS siswa (Siswono, 2018), dan (2) Terdapat kesalahan dalam memahami apa yang dimaksud dengan Soal HOTS (Tanujaya \& Mumu, 2020).

Lalu bagaimana seharusnya pembelajaran matematika di Indonesia, khususnya siswa di Tanah Papua? Bentuk soal matematika berbasis ethnic Papua bagaimana yang dapat digunakan untuk mengembangkan HOTS siswa? Oleh karena itu penelitian ini dilakukan dengan tujuan untuk mengembangkan dan menganalisis beberapa bentuk soal matematika yang mampu mengembangkan HOTS siswa. Soal-soal HOTS tersebut dikembangkan berbasis Alam dan Budaya Papua

\section{METODE PENELITIAN}

Penelitian ini dilaksanakan dengan menggunakan metode penelitian dan pengembangan (Research and Development Method, R\&D). R\& D merupakan metode penelitian yang dilaksanakan untuk mencapai pengetahuan baru yang mungkin diterapkan untuk menciptakan teknologi, produk, layanan, atau sistem baru. Tujuan dari proses ini adalah untuk mengembangkan strategi baru atau yang lebih baik untuk mencapai tujuan yang spesifik dengan baik (NCF, 2013). Dalam penelitian ini produk baru yang hendak dihasilkan adalah butir soal HOTS yang berbasis Alam dan Budaya Papua.

Terdapat 4 (empat) tahapan dalam pelaksanaan penelitian, yaitu: penetapan konteks, pengembangan butir soal, uji validitas butir, dan analisis butir terpilih. Secara terperinci, penelitian dilaksanakan sebagai berikut:

1. Penetapan konteks yang akan digunakan. Terdapat tiga konteks yang digunakan untuk mengembangkan butir soal HOTS dalam penelitian ini, yaitu: Tarian Tumbu Tanah, Rumah Kaki Seribu, dan Kupu-kupu Sayap Burung. 
2. Pengembangan butir soal untuk masing-masing konteks. Terdapat tiga butir soal yang dikembangkan untuk masing-masing konteks. Tiga butir soal HOTS untuk masing-masing konteks kemudian diuji validitasnya oleh pakar untuk memilih butir terbaik untuk masing-masing konteks.

3. Uji validitas dilakukan oleh pakar secara kualitatif. Indikator yang digunakan pakar untuk menguji adalah: (a) penyelesaiannya membutuhkan pemahaman alam dan budaya Papua (b) bukan merupakan soal rutin, dan (c) penyelesaian membutuhkan penggunaan beberapa konsep matematika.

4. Analisis lebih lanjut dilakukan untuk memaparkan kelayakan soal tersebut dikelompokkan sebagai soal HOTS yang berbasis Alam dan Budaya Papua.

\section{HASIL DAN PEMBAHASAN}

Pembelajaran matematika dan juga pembelajaran lainnya, seharusnya didasarkan pada pembelajaran yang berbasiskan pembelajaran aktif (Active Learning). Beberapa pembelajaran aktif yang dapat digunakan untuk meningkatkan HOTS siswa, antara lain: Problem Based Learning (Jailani, Sugiman, \& Apino, 2017), Problem Solving (Herutomo,, \& Masrianingsih, 2019), Project Based Learning, Discovery Learning, dan Inquiry Learning (Siswono, 2018; Minarni, \& Napitupulu, 2020). Apakah model-model pembelajaran tersebut belum diterapkan dalam pembelajaran ril di Indonesia, khususnya di Papua? jawabannya sudah. Namun hanya dilakukan sebatas pada waktu guru atau dosen melaksanakan penelitian. Setelah kegiatan tersebut, umumnya pembelajaran kembali dilakukan seperti biasanya (Tanujaya \& Mumu, 2020).

Pembelajaran aktif merupakan pembelajaran yang melibatkan siswa dalam seluruh aktifitas pembelajaran. Pembelajaran aktif memfasiltasi siswa untuk terlibat secara aktif dalam mengakses sumber-sumber belajar. Pembelajaran aktif memungkinkan siswa untuk mengembangkan kemampuan berpikir, khususnya kemampuan berpikir tingkat tinggi - HOTS. Guna mewujudkan hal tersebut, maka pembelajaran matematika harus dimulai dari apa yang dketahui dan dikenal siswa. Salah satu cara yang dapat dilakukan adalah penggunaan konteks lokal dalam pembelajaran matematika.

\section{Konteks lokal dalam pembelajaran matematika di tanah Papua}

Pembelajaran matematika di tanah Papua, khususnya di Papua Barat sudah 
seharusnya tidak menghasilkan siswa yang berpikir mengikuti algoritma tertentu. Siswa harus merdeka mengembangkan pemikirannya, sesuai dengan konsep merdeka belajar yang diperkenalkan kembali oleh Menteri Pendidikan dan Kebudayaan. Pembelajaran yang mengembangkan kemampuan berpikir tingkat tinggi.

Pembelajaran matematika yang selama ini dimulai dari penjelasan konsep, pemberian contoh, mengerjakan latihan, telah menghasilkan siswa yang hanya mengandalkan kemampuan berpikir menggunakan algoritma tertentu (Tanujaya, Prahmana, \& Mumu, 2017). Pada saat menghadapi soal yang agak berbeda, siswa mulai kebingungan dan tidak mampu menyelesaikannya.

Dilain pihak, pembelajaran untuk mengembangkan HOTS siswa berdasarkan prinsip konstruktivisme perlu dikembangkan di Tanah Papua. Siswa harus dididik untuk menemukan sendiri konsep yang hendak dipelajarinya. Pembelajaran tersebut dimulai dari apa yang dikenal dan diketahuinya, khususnya dalam kehidupan sehari-hari siswa. Dengan demikian pada waktu menghadapi soal yang berbeda, siswa dapat menggunakan kemampuan HOTS untuk menyelesaikannya. Pada akhirnya setelah lulus nanti, pada masa yang akan datang, mereka mampu menyesuaikan diri, bahkan keluar sebagai pemenang, jika menghadapi berbagai permasalahan.

Oleh karena itu soal matematika yang dikembangkan sudah seharusnya berbasis alam dan budaya (ethnic based) Papua. Langkah pertama yang perlu dilakukan adalah upaya pembenahan terhadap buku pelajaran matematika dan LKS yang digunakan siswa secara berkesinambungan. Penulisan dan pengembangan buku pelajaran Matematika berbasis HOTS, yang kontekstual Papua, khususnya Papua Barat. Lebih spesifik lagi Kontekstual Suku Besar Arfak.

Nenek moyang rakyat Papua, khususnya leluhur suku besar Arfak, telah menggunakan konsep matematika dalam membangun Rumah Kaki Seribu (Mumu dan Aninam, 2018), Tarian Tumbu Tanah, dan Kupu-kupu sayap burung (Tanujaya, 2020). Konteks-konteks tersebut berpeluang digunakan untuk mengembangkan soal HOTS matematika berbasis alam dan budaya Papua.

Penggunaan alam dan budaya untuk mengembangkan HOTS siswa dalam pembelajaran matematika pertama kali diperkenalkan oleh Tanujaya dalam Pidato Pengukuhannya sebagai Guru Besar Pendidikan Matematika di Universitas Papua, yang dinyatakan dalam istilah "Ethnic-HOTS" (Tanujaya, 2020). Contoh hasil pengembangan 
butir soal HOTS yang berbasis alam dan budaya Papua, disajikan berikut ini.

\section{Konteks Tarian Tumbu Tana}

Tari Tumbu Tanah adalah salah satu tarian tradisional dari Suku Besar Pegunungan Arfak di Provinsi Papua Barat. Tarian ini biasa ditampilkan untuk menyambut tamu-tamu penting dan perayaan besar lainnya.

Contoh soal matematika HOTS yang menggunakan konteks tarian Tumbu Tanah, sebagai berikut:

Gunakan angka-angka 2, 6, 10, 12, 18, dan 30, untuk melengkapi pernyataan berikut. Misalkan, dalam perayaan ulang tahun Kabupaten Gunung Arfak, diadakan tarian Tumbu Tanah. Pada waktu pelaksanaannya jumlah perempuan lebih banyak dari jumlah laki-laki, dimana terdapat .......... orang penari, yang terdiri dari ..... laki-laki, dan ..... perempuan. Dari jumlah perempuan yang ikut menari, terdapat ....... perempuan yang sudah tua, ..........perempuan dewasa, dan ..... anak-anak perempuan.

Soal tersebut dapat dimodifikasi dengan tidak menampilkan angka untuk dipilih, tetapi siswa diminta untuk menentukan angka yang dapat digunakan untuk menjawab pernyataan tersebut. Agar dapat menyelesaikan soal tesebut, siswa diharapkan telah memahami beberapa konsep bilangan, seperti urutan bilangan dan operasi bilangan.

\section{Konteks Rumah Kaki Seribu}

Rumah tradisional kaki seribu merupakan rumah tradisional masyarakat Pegununagn Arfak. Rumah ini terbuat dari $100 \%$ bahan alami dan strukturnya memiliki banyak tiang, sehingga disebut rumah kaki seribu. Tiang penyangga sekunder disusun mengelilingi tiang utama dengan mengikuti pola susunan tiang utamanya. Pada rumah kaki seribu tradisional, atap rumah terbuat dari ilalang yang disusun dalam bentuk persegi Panjang.

Contoh soal matematika HOTS yang menggunakan konteks rumah Kaki Seribu, sebagai berikut:

Atap Rumah Kaki seribu terbuat dari alang-alang (ilalang), umumnya berbentuk persegi panjang dengan Panjang 1,5 meter dan lebar 0.6 meter. Berdasarkan informasi dari beberapa rumah Kaki Seribu, diketahui bahwa pada salah satu sisi atapnya, diperoleh 
informasi sebagaimana disajikan pada Tabel 2.

Tabel 2. Ukuran atap ilalang pada beberapa Rumah Kaki Seribu

\begin{tabular}{|c|c|c|c|c|c|}
\hline \multirow{2}{*}{ No } & \multirow{2}{*}{$\begin{array}{l}\text { Panjang } \\
\text { Atap (m) }\end{array}$} & \multirow{2}{*}{$\begin{array}{l}\text { Lebar Atap } \\
\text { (m) }\end{array}$} & \multicolumn{3}{|c|}{ Jumlah Atap Ilalang } \\
\hline & & & Horisontal & Vertikal & Total \\
\hline 1 & 8 & 6 & 6 & 5 & 30 \\
\hline 2 & 8 & 6 & 7 & 5 & 35 \\
\hline 3 & 8 & 6 & 6 & 6 & 36 \\
\hline 4 & 10 & 6 & 8 & 5 & 40 \\
\hline 5 & 10 & 8 & 7 & 7 & 49 \\
\hline 6 & 10 & 8 & 8 & 8 & 64 \\
\hline
\end{tabular}

Jika salah satu sisi bagian atap rumah Kaki Seribu yang hendak dibangun, panjangnya adalah 12 meter dan lebar 10 meter, maka berapakah jumlah atap ilalang yang dibutuhkan untuk membangun rumah Kaki Seribu tersebut.

Pada waktu menjawab pertanyaan tersebut, peluang siswa mempunyai jawaban yang beragam sangat besar. Tidak ada jawaban yang paling benar, tetapi beberapa aspek yang dapat digunakan sebagai pertimbangan, seperti kekuatan bagian atap yang diinginkan, dan efisiensi penggunaan bahan. Semakin rapat atap yang di tumpang tindihkan maka semakin kuat atas yang dibangun, tetapi semakin banyak atap yang digunakan. Satu hal yang pasti, siswa tidak dapat secara langsung membagi Panjang bagian atap dengan Panjang atap ilalang yang diketahui.

\section{Konteks Kupu-kupu Sayap Burung}

Kupu-kupu sayap burung adalah jenis Ornithoptera goliath atau dikenal dengan nama Goliath Birdwing. Kupu kupu ini mempunyai habitat asli di Pegunungan Arfak, Manokwari Papua Barat. Kupu-kupu ini memiliki rentang sayap mencapai 18 hingga 23 centimeter

Contoh soal matematika HOTS yang menggunakan konteks kupu-kupu Sayap Burung, sebagai berikut:

Seekor kupu-kupu sayap burung diketahui melakukan dua aktifitas utama, yaitu terbang dan hinggap di pohon atau tempat tertentu. Kedua fenomena tersebut dinyatakan pada Grafik pada Gambar 1. 
Jika sumbu x adalah waktu dalam detik, sedangkan sumbu-y adalah jarak dari dari pohon pertama (dalam meter), maka gunakan data dan informasi tersebut untuk menjawab beberapa pertanyaan berikut:

1. Apakah kupu-kupu kembali ke pohon pertama?

2. Berapa kali kupu-kupu beristirahat sebelum kembali ke pohon pertama?

3. Berapa jumlah pohon yang dihinggapi kupu-kupu?

4. Pada periode waktu tertentu, tentukan kupu-kupu yang mempunyai kecepatan tertinggi?

5. Apakah kupu-kupu selalu terbang dengan kecepatan yang konstan?

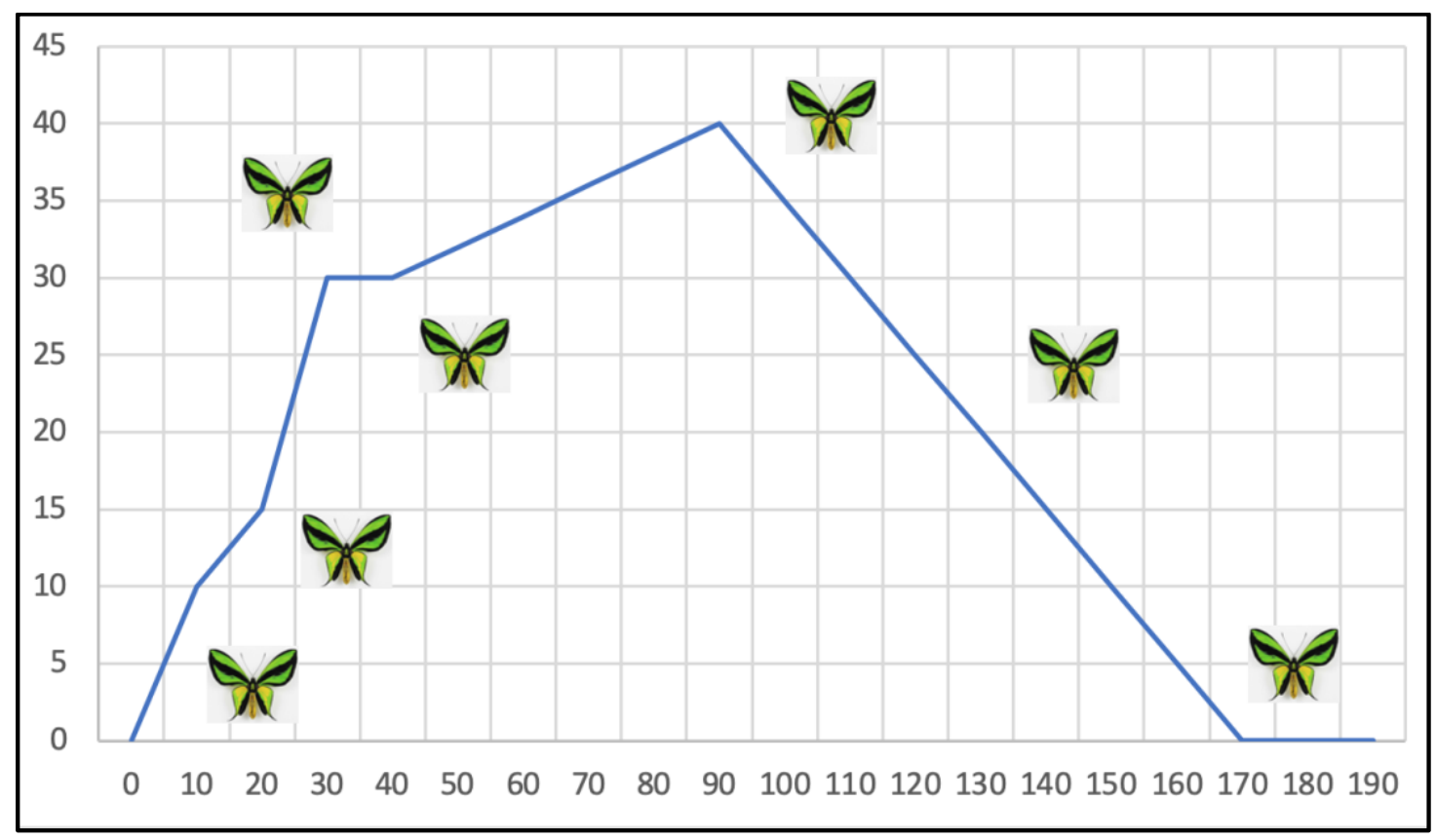

Gambar 1. Jarak antara kupu-kupu dan pohon pertama yang dihinggapi

Agar dapat menyelesaikan persoalan tersebut, siswa harus memiliki HOTS yang sangat baik, khususnya kemampuan memahami data yang disajikan pada grafik, atau yang dikenal sebagai literasi data. Oleh karena itu, sebelum menjawab pertanyaan tersebut siswa harus mampu menganalisis data dan informasi yang terdapat pada grafik tersebut. Setelah itu, siswa harus memahami konsep matematika, seperti waktu, jarak, dan kecepatan dengan baik. Tanpa memahami beberapa konsep matematika tersebut, siswa tidak akan mampu menyelesaikan soal tersebut. 


\section{KESIMPULAN}

Soal HOTS dapat dikembangkan berbasiskan Alam dan Budaya Papua. Beberapa indikator yang dapat digunakan untuk mengembangkan soal HOTS berbasis alam dan budaya Papua adalah: harus memahami karakteristik alam dan budaya Papua; bukan merupakan soal rutin; dan penyelesaian membutuhkan penggunaan beberapa konsep matematika. Soal HOTS berbasiskan Alam dan Budaya Papua berpotensi untuk digunakan sebagai muatan lokal dalam pembelajaran matematika di Tanah Papua. Hasil penelitian ini diharapkan dapat menggugah pendidik dan peneliti lainnya untuk mengembangkan soal-soal HOTS berbasis alam dan budaya Papua.

\section{DAFTAR PUSTAKA}

Herutomo, R. A., \& Masrianingsih, M. (2019). Pembelajaran Model Creative Problem Solving Untuk Mendukung Higher-Order Thinking Skills Berdasarkan Tingkat Disposisi Matematis. Jurnal Riset Pendidikan Matematika, 6(2), 188-199.

Jailani, J., Sugiman, S., \& Apino, E. (2017). Implementing the Problem-Based Learning in Order to Improve the Students' HOTS and Characters. Jurnal Riset Pendidikan Matematika, 4(2), 247-259.

Kemdikbud. (2013). Permendikbud Nomor 69 Tahun 2013 tentang Kerangka Dasar dan Struktur Kurikulum SMA/MA. Jakarta: Kemendikbud

Kemdiknas. (2006). Permendiknas Nomor 22 Tahun 2006 tentang Standar Isi untuk Satuan Pendidikan Dasar dan Menengah. Jakarta: Kemendiknas

Minarni, A., \& Napitupulu, E. E. (2020). The Role of Constructivism-Based Learning in Improving Mathematical High Order Thinking Skills of Indonesian Students. Infinity: Journal of Mathematics Education, 9(11), 111-132.

Moore, B., \& Stanly, T. (2010). Critical Thinking and Formative Assessments. Larchmount. New York: Eye on Education, Inc.

Mumu J., \& Aninam, P. A. (2018). Analisis Konteks Asal Budaya Papua dalam Pendidikan Matematika Realistik. Journal of Honai Math, 1(1), 24-33.

National Science Foundation. (2013). Commond guidelines for education research and development. Washington: Institute of Education Sciences.

OECD. (2004). First Result from PISA: Executive Summary. Paris: OECD Publishing.

OECD. (2007). Executive Summary PISA 2006: Science Competencies for Tomorrow's World. Paris: OECD Publishing.

OECD. (2010). PISA 2009 Results: Executive Summary. Paris: OECD Publishing. 
OECD. (2013). PISA 2012 Results In Focus: What 15-Year-olds know And What They can Do with What They Know. Paris: OECD Publishing.

OECD. (2016). PISA Results 2015: Excellence and Equity in Education. Paris: OECD Publishing.

OECD. (2019). PISA Results 2018: Combined Executive Summary. Paris: OECD Publishing.

Siswono, T. Y. E. (2018). Pembelajaran Matematika Berbasis Pengajuan dan Pemecahan Masalah. Bandung: Remaja Rosdakarya.

Tanujaya, B. (2020). Ethnic-HOTS Instruction Berbasis Budaya dan Alam Papua: Alat Ukur Pembelajaran Matematika Siswa Tanah Papua yang Berdaya Saing Global, Pidato Pengukuhan Guru Besar Pendidikan Matematika. Manokwari: Universitas Papua.

Tanujaya, B., \& Mumu J. (2020). Students' Misconception of HOTS Problems in Teaching and Learning of Mathematics. Journal of Physics: Conference Series, 1657(1), 012081

Tanujaya, B., Mumu, J., \& Margono, G. (2017). The Relationship between Higher Order Thinking Skills and Academic Performance of Student in Mathematics Instruction. International Education Studies, 10(11), 78-85.

Tanujaya, B., Prahmana, R. C I., \& Mumu, J. (2017). Mathematics Instruction, Problems, Challenges and Opportunities: A Case Study in Manokwari Regency, Indonesia. World Transactions on Engineering and Technology Education, 15(3), 287-291.

Yee, M. H., Md Yunos, J., Hassan, R., Tee, T. K., Mohamad, M. M., \& Othman, W. (2015). Disparity of Learning Styles and Higher Order Thinking Skills among Technical Students. Procedia - Social and Behavioral Sciences, 204, 143-152. 
Journal of Honai Math, Vol. 3, No. 2, pp. 157-168, Oktober 2020

Tanujaya \& Muтu, Pengembangan dan Analisis Soal Higher Order Thinking Skills Berbasis Alam dan Budaya Papua 